\title{
EFEITOS DE POTENCIAIS DE ÁGUA NO SOLO, EM DIFERENTES ESTÁDIOS FENOLÓGICOS DA CULTURA DA CEVADA (Hordeum vulgare L.) ${ }^{1}$
}

\author{
M.A. URCHEI; J.D. RODRIGUES \\ Depto. de Botânica - IB/UNESP - C.P. 505, CEP: 18603-970 - Botucatu,SP
}

\begin{abstract}
RESUMO: Objetivándo avaliar os efeitos de défices hídricos, em trés estádios fenologicos da cultura da cevada (Hordeum vulgare L.), foi condurido experimento em vasos, com delineamento em blocos ao acaso. Foram utilizados nove tratamentos decorrentes da combinação dos potenciais minimos de água no solo de $-0,05,-0,20$ e $-1,50 \mathrm{MPa}$, com os estadios fenologicos de maximo perfilhamento, norescimento e grấo leitoso, permanecendo uniformizados durante o restante do ciclo, entre os potenciais de $-0,01$ a $-0,05 \mathrm{MPa}$. Os resultados de produção, peso e teor de proténa dos grãos, tamanho de espigas, número total e número de espigas chochas, mostraram que os efeitos de défices hídricos variaram com a intensidade, duração e estádio fenológico da cultura, onde o estádio de florescimento mostrou-se mais sensivel ao défice de água. A ocorrência de défice hídrico intenso, em cada um dos estadios, bem como ciclos repetidos de defices moderados ou intensos, levaram a diminuiçōes significativas na produção de grãos, além de ocorrer tendência ao aumento do teor de proteína dos grāos. $O$ manejo da irrigação na cultura da cevada, quando se busca a máxima eficiencia no uso da água, deve levar em conta os diferentes estádios fenologicos.

Descritores: potencial hidrico do solo, cevada, fases fenologicas
\end{abstract}

\section{EFTECTS OF SOIL WATER POTENTIALS AT DIFFERENT PHENOLOGICAL PHASES OF BARLEY CROP (Hordeun vulgare L.)}

\begin{abstract}
ARSTRACT: The experiment was carried out under greenhouse conditions, with the objective of evaluating the effects of water deficits in three phenological phases of barley crop (Hordeum vulgare L.). Pots were arranged in a randomized block design with nine treatments. They originated from the combination of minimum soil water potentials of $-0,05,-0,20$ and $-1,50 \mathrm{MPa}$, with the phenological phases of maximum tillering, flowering and milky grain, having been hold uniformly along the rest of the cycle, between $-0,01$ and $-0,05 \mathrm{MPa}$ potentials. Weight of grain, protein content, spike sizes, spike total number and number of hollow spikes, showed that water deficit effects varied with the intensity, duration and phenological phase of the crop, where the flowering phase showed to be most sensitive to the water deficit. Ocurrence of intense water deficit in each phase, as well as repeated cycles of moderated or intense water deficits, led to significative reductions in grain production. Besides, a tendency to a higher grain protein content was observed. Irrigation manegement of barley crop, aiming to a maximum efficience in water consumption must take into account the different phenological phases.
\end{abstract}

Key-Words: soil water potentials, barley, phenological phases.

\section{INTRODUÇÃO}

A cevada é o quarto cereal de maior produção e consumo no mundo, apresentando características próprias, as quais possibilitam seu cultivo em regiões onde a alcalinidade dos solos, geadas e secas dificultam o cultivo de outros cereais (MINELLA et al., 1981).

Contudo, embora possa ser utilizada como ração animal, como farinha para alimentação humana, para fins terapêuticos e como forrageira verde de inverno, seus grãos têm sido destinados, principalmente, ao preparo do malte, onde alcançam os melhores preços. No Brasil, as limitaçóes do cultivo da cevada aos estados da região sul do país, têm levado à produções insuficientes, fazendo com que o mercado interno recorra, sistematicamente, à importação.

Assim, buscando viabilizar a ampliação territorial da cevada no Brasil, $\epsilon$ fundamental o

1 Parte de Dissertação do $1^{\circ}$ autor apresentada à Faculdade de Ciências Agronômicas/UNESP, Botucatu.

Sci. agric., Piracicaba, 51(3):533-540, set./dez., 1994 
conhecimento das necessidades hídricas da cultura, tendo em vista que as precipitações pluviométricas, durante o período em que o cereal é normalmente cultivado, raramente atendem suas exigências.

De maneira geral, para que o desenvolvimento das espécies vegetais ocorra de modo satisfatório, ou seja, para que a acumulação de matéria seca, decorrente da síntese de carboidratos, se processe de maneira btima, os fatores água e luz são essenciais, evidenciando a importância da irrigação como mecanismo de suprir possíveis deficiências hídricas, durante o ciclo fenológico das culturas.

Por outro lado, vários trabalhos na literatura têm revelado que os efeitos dé défices hídricos, sobre a produtividade das espécies vegetais, variam com o estádio, em que o mesmo se manifesta, existindo períodos críticos, onde as plantas são mais sensíveis a diminuição da disponibilidade de água no solo (ROBINS \& DOMINGO, 1953; DENMEAD \& SHAW, 1960; ASPINAL et al., 1964; SALTER \& GOODE, 1967; KRAMER, 1969; SCALOPPI, 1973; LAWLOR et al., 1981; URCHEI, 1992).

Segundo SALTER e GOODE (1967), o período em que a cultura da cevada é mais sensível à défices hídricos, vai do final do desenvolvimento vegetativo ate o espigamento, quando se formam os 6rgãos reprodutivos.

WELLS e DUBETZ (1970) e MILLAR (1984), afirmam que o período crítico ao défice de água na cultura da cevada, vai da fase de formação das espigas até a fase de grãos no estado leitoso.

LAWLOR et al. (1981), verificaram que o período compreendido entre a emergência e a antese na cultura da cevada, foi particularmente sensível à défice hídrico, diminuindo significativamente $o$ índice de área foliar, além de antecipar a senescência das folhas.

URCHEI (1992), verificou que os efeitos de défices hídricos, sobre a produção de grãos de cevada, variaram com a intensidade, duração e estádio fenológico da cultura, onde o estádio de florescimento caracterizou-se como o mais sensível à défices de água.

Uma vez que as culturas respondem diferentemente a diminuição do potencial de água no solo, de acordo com o estádio fenológico de sua ocorrência, parece provável que o manejo adequado e racional da água de irrigação, buscando a máxima eficiência no uso da água, deve levar em consideração os potenciais mínimos de água no solo, em cada estádio fenológico (SCALOPPI, 1973).
Neste sentido, o presente trabalho teve por objetivo avaliar os efeitos de défices hídricos, em três estádios fenológicos da cultura da cevada (Hordeum vulgare L.), sobre a produção final de grãos e seus componentes.

\section{MATERIAL E METODOS}

O experimento foi conduzido em casa de vegetação da Área Experimental do Departamento de Botânica, do Instituto de Biociências, do Campus de Botucatu - UNESP, durante os meses de maio a setembro de 1991, a uma altitude média de $\mathbf{8 0 0}$ metros.

O solo utilizado foi classificado por CARVAlHo et al. (1983) como Terra Roxa Estruturada "integrade" para Latossolo Vermelho Escuro, distrófico, textura média argilosa, com os resultados da análise mecânica constantes nas TABELAS 1 e 2 e química na TABELA 3.

TABELA 1. Resultados da análise granulométrica e classe textural.

\begin{tabular}{|c|c|c|}
\hline \multicolumn{2}{|c|}{ Valores em porcentagem } & \multirow{2}{*}{$\begin{array}{l}\text { Classe } \\
\text { Textural }\end{array}$} \\
\hline Areia & Silte Argila & \\
\hline Amg Ag Am Af Amf Total & & \\
\hline $\begin{array}{llllll}0,2 & 2,4 & 18,4 & 19,1 & 5,7 & 45,8\end{array}$ & $25,1 \quad 29,1$ & $\begin{array}{l}\text { franco } \\
\text { argiloso }\end{array}$ \\
\hline
\end{tabular}

TABELA 2. Resultados da densidade de partículas, densidade global e porosidade total.

\begin{tabular}{lcc}
\hline $\begin{array}{c}\text { Densidade de } \\
\text { particulas } \\
(\mathrm{g} / \mathrm{cm} 3)\end{array}$ & $\begin{array}{c}\text { Densidade } \\
\text { global } \\
(\mathrm{g} / \mathrm{cm} 3)\end{array}$ & $\begin{array}{c}\text { Porosidade } \\
\text { total } \\
(\%)\end{array}$ \\
\hline 2,45 & 1,20 & 51,02 \\
\hline
\end{tabular}

$O$ delineamento experimental foi o de blocos ao acaso, com nove tratamentos decorrentes da combinação dos potenciais mínimos de água no solo de $-0,05,-0,20$ e $-1,50 \mathrm{MPa}$, com os estádios fenol6gicos de máximo perfilhamento, florescimento e grão leitoso, permanecendo uniformizados 
durante o restante do ciclo, entre os potenciais de $-0,01$ e $-0,05 \mathrm{MPa}$ (TABELA 4).

TABELA 3. Resultados da análise química do solo utilizado no experimento, expressos por volume de terra fina seca ao ar (TFSA).

pH m.o. P.resina $\mathrm{K}$ Ca $\mathrm{Mg} \mathrm{H}+\mathrm{Al}$ SB CTC V

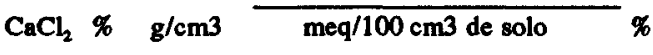

\begin{tabular}{llllllllll}
\hline 5,2 & 1,7 & 7 & 0,2 & 2,4 & 1,3 & 2,5 & 3,9 & 6,4 & 61
\end{tabular}

Para o acompanhamento dos parâmetros estudados, foram instalados dois blocos, com seis repetições em cada um, perfazendo um total de 12 repetições para cada tratamento. Além disso, o experimento constou de mais quatro repetições para a correção do peso dos vasos, devido ao aumento da fitomassa de cada unidade experimental, durante o desenvolvimento do ciclo fenológico.

TABELA 4. Caracterização dos tratamentos, com os respectivos estádios fenológicos da cultura.

Tratamentos

Estádios fenológicos

\begin{tabular}{|c|c|c|}
\hline $\begin{array}{l}\text { Máximo } \\
\text { perfilhamento }\end{array}$ & Florescimento & $\begin{array}{l}\text { Grão } \\
\text { leitoso }\end{array}$ \\
\hline
\end{tabular}

\begin{tabular}{llll}
\hline 1 & I* & I & I \\
2 & S1** & I & I \\
3 & I & S1 & I \\
4 & I & I & S1 \\
5 & S2*** & I & I \\
6 & I & S2 & I \\
7 & I & I & S2 \\
8 & S1 & S1 & S1 \\
9 & S2 & S2 & S2 \\
\hline
\end{tabular}

* I = irrigado $(-0,01$ a $-0,05 \mathrm{MPa})$

** $S 1$ = défice moderado $(-0,15$ a $-0,20 \mathrm{MPa})$

*** S2 = défice intenso $(-1,00$ a $-1,50 \mathrm{MPa})$

Cada unidade experimental constou de um vaso plástico impermeável, contendo 8.000 $g$ de terra fina seca ao ar, retirada da camada de 0-20 cm de profundidade, e passada em peneira de $5 \mathrm{~mm}$ de malha.

Sci. agric., Piracicaba, 51(3):533-540, set./dez., 1994
Foram coletadas amostras representativas de cada grupo de 5 vasos e levadas em estufa a $1050 \mathrm{C}$, até peso constante, para posterior determinação da umidade do solo, com base em peso seco, a qual foi utilizada, juntamente com a curva característica do solo, no controle dos potenciais de água definidos em cada tratamento.

De acordo com os resultados da análise química do solo, cada vaso recebeu, antes da semeadura, $150 \mathrm{ppm}$ de fósforo elementar, 60 ppm de potássio elementar e $60 \mathrm{ppm}$ de nitrogênio elementar, não sendo necessária a correção do $\mathrm{pH}$. A adubação preconizada foi feita vaso por vaso, utilizando-se de uma caixa de fibra sintética, para homogeneizar adequadamente os adubos com o solo de cada unidade experimental. A partir do vigésimo quinto dia após a semadura, foram aplicados, semanalmente, $200 \mathrm{ml}$ de solução nutritiva completa de micronutrientes por vaso (WAUGH \& FITTS, 1966), na concentração de 1\%. Aos 30 dias após a semeadura, procedeu-se a adubação de cobertura, colocando-se $25 \mathrm{ppm}$ de nitrogênio elementar por vaso, diluídos em $200 \mathrm{ml}$ de água.

A semeadura foi realizada dia $18 / 05 / 91$, à uma profundidade média de $1,5 \mathrm{~cm}$, colocando-se 15 sementes da cultivar FM-519 de cevada cervejeira (Hordeum vulgare L.) por vaso, tratadas previamente com fungicida à base de THIRAM, na dosagem de $300 \mathrm{~g}$ do produto comercial por $100 \mathrm{Kg}$ de semente. Em seguida, foram adicionados em torno de $1.000 \mathrm{ml}$ de água por vaso, para possibilitar uma germinação adequada das sementes.

Após a emergência e desenvolvimento inicial das plântulas, realizaram-se dois desbastes, deixando cada vaso com quatro plantas.

Para minimizar os efeitos da evaporação e melhorar a uniformidade entre os tratamentos, os vasos foram cobertos com filme plástico flexível transparente, quando as plantas estavam com 23 dias após a semeadura.

A diferenciação dos tratamentos teve início aos 35 dias apos a semeadura, seguindo os períodos e datas conforme a TABELA 5.

No controle das irrigações, os vasos eram pesados diariamente em balança com sensibilidade de um grama, entre 8:00 e 10:00 horas, para posterior reposição da água evapotranspirada no período, sempre que necessário.

Ao longo do desenvolvimento do ciclo da cultura, foram efetuadas pulverizações semanais preventivas, com inseticida e acaricida organofosfo.rado sistêmico, contendo 240 gramas de fosfato 
2-carbometoxi-1-metil-vinil-dimetila por litro, em formulação concentrada emulsionável (CE), na dosagem de $\mathbf{0 , 2 \%}$.

TABELA 5. Períodos das diferenciações dos tratamentos e dias após a semeadura (DAS).

\begin{tabular}{ccc}
\hline $\begin{array}{c}\text { Diferenciação dos } \\
\text { tratamentos }\end{array}$ & Datas & DAS \\
\hline 1a. & 22 a $28 / 06 / 91$ & $35-41$ \\
2a. & 22 a $28 / 07 / 91$ & $65-71$ \\
3a. & 17 a $23 / 08 / 91$ & \\
\hline
\end{tabular}

A última irrigação do experimento, deu-se aos 100 dias após a semeadura. A partir daí, os tratamentos foram acompanhados até a maturação completa das espigas, o que ocorreu aos 121 dias após a semeadura, data em que realizou-se a colheita final do experimento.

Para a avaliação dos parâmetros de produção, foram feitas as seguintes medições: produção final de grãos (estimada através da somatória da matéria seca de grãos de quatro plantas e expressa em gramas); peso de 100 grãos (determinado de acordo com as Regras para Análise de Sementes do DNPV/DISEM do Ministério da Agricultura, Portaria no. 532 de 29/07/76); teor de proteína dos grãos (realizado conforme Portaria no. 389 de 09/05/79, do Ministério da Agricultura); tamanho médio das espigas (determinado através da média aritmética entre os tamanhos de todas as espigas de quatro plantas, em centímetros); número total de espigas (caracterizado pelo somatório total de espigas existentes em cada tratamento); e número de espigas chochas (definido como as espigas que apresentaram 50\% mais um de grãos chochos).

\section{RESULTADOS E DISCUSSÃO}

As médias de produção final de grãos, peso de 100 grãos e teor de proteína dos grãos podem ser vistas na TABELA 6 e Figura 1, enquanto a análise de variância encontra-se na TABELA 7.

Com relação à produção de grãos, a análise de variância, entre os diferentes tratamentos, mostra significância estatística em nível de $1 \%$ de probabilidade. Assim, a comparação das médias, pelo teste Tukey, evidencia o decréscimo deste parâmetro com a intensificação e repetição de ciclos de défices hídricos, sendo que esse decréscimo se manifestou com maior ou menor intensidade, dependendo do estádio fenológico de ocorrência dos diferentes níveis de défices. Dessa forma, verifica-se que os maiores valores de produção de grãos, ocorreram nos tratamentos 1 (irrigado diariamente), 2 (défice moderado no estádio de máximo perfilhamento) e 4 (défice moderado no estádio de grão leitoso), não apresentando significância estatística entre si, apesar de o tratamento 1 (irrigado), mostrar a maior produção final de grãos. A seguir, os tratamentos 3 (défice moderado no estádio de florescimento), 5 (défice intenso no estádio de máximo perfilhamento) e 7 (défice intenso no estádio de grão leitoso), tiveram uma produção de grãos, em torno de $80 \%$ da produção verificada no tratamento irrigado. Em seguida, o tratamento 8 (submetido a três ciclos de défices moderados, nos estádios de máximo perfilhamento, florescimento e grão leitoso), teve produção de grãos em torno de $61 \%$ do tratamento irrigado, ficando o tratamento 6 (défice intenso no estádio de florescimento), logo depois, com $53 \%$ da produção relativa de grãos. Por último, o tratamento 9 (sob três ciclos de défices intensos, nos três estádios fenológicos), mostrou uma produção relativa de grãos, em torno de $42 \%$ do tratamento irrigado, sendo o menos produtivo.

TABELA 6. Médias de produção final de grãos (g), peso de 100 grãos (g) e teor de proteína dos grãos (\%).

\begin{tabular}{llll}
\hline Trat. & $\begin{array}{l}\text { Produção } \\
\text { de grãos }\end{array}$ & $\begin{array}{c}\text { Peso de } \\
100 \text { grãos }\end{array}$ & $\begin{array}{c}\text { Proteína } \\
\text { dos grãos }\end{array}$ \\
\hline 1 & $27,864 \mathrm{~A}\left(^{*}\right)$ & $5,229 \mathrm{~A}$ & $9,34 \mathrm{~B}$ \\
2 & $25,780 \mathrm{AB}$ & $4,534 \mathrm{AB}$ & $9,72 \mathrm{AB}$ \\
3 & $21,914 \mathrm{BC}$ & $4,628 \mathrm{AB}$ & $9,50 \mathrm{AB}$ \\
4 & $26,065 \mathrm{~A}$ & $4,860 \mathrm{AB}$ & $9,97 \mathrm{AB}$ \\
5 & $22,013 \mathrm{BC}$ & $4,425 \mathrm{~B}$ & $9,72 \mathrm{AB}$ \\
6 & $14,868 \mathrm{DE}$ & $4,584 \mathrm{AB}$ & $10,44 \mathrm{AB}$ \\
7 & $21,711 \mathrm{C}$ & $4,312 \mathrm{~B}$ & $10,12 \mathrm{AB}$ \\
8 & $17,042 \mathrm{D}$ & $4,692 \mathrm{AB}$ & $10,14 \mathrm{AB}$ \\
9 & $11,562 \mathrm{E}$ & $4,108 \mathrm{~B}$ & $11,72 \mathrm{~A}$ \\
\hline Médias & 20,982 & 4,597 & 10,07 \\
\hline
\end{tabular}

(*) As letras representam a comparação, em cada coluna, pelo teste Tukey, sendo que letras iguais, representam médias que não diferem significativamente entre si. 


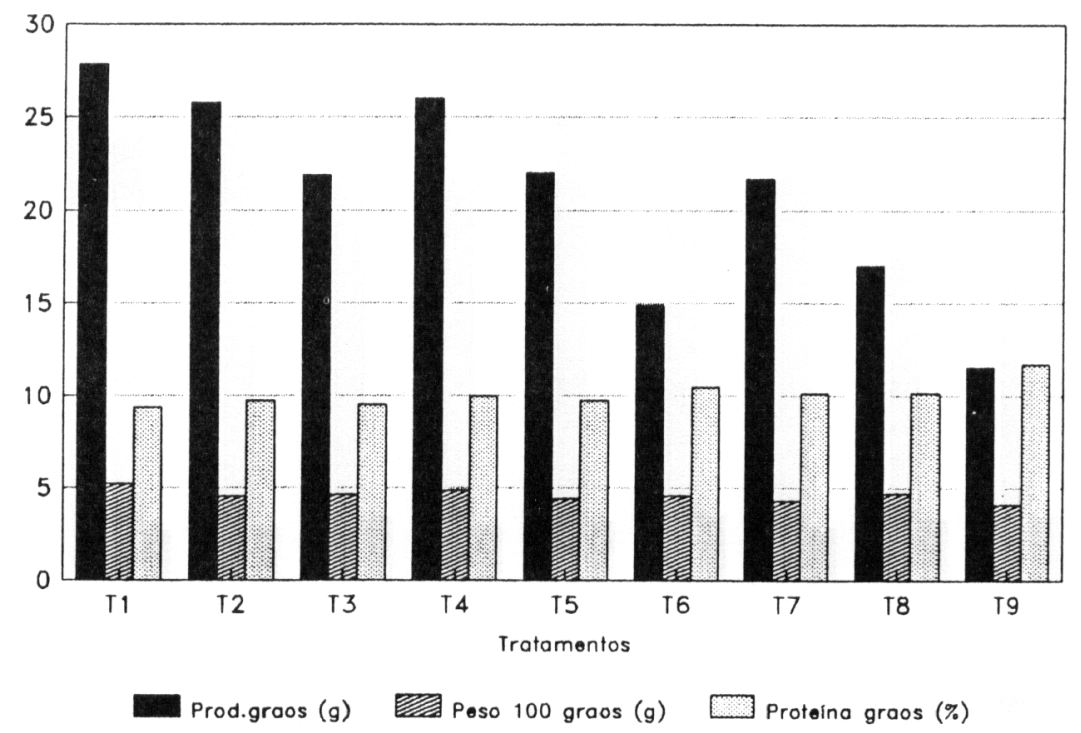

Figura 1. Médias de produção final de grãos (g), peso de 100 grãos (g) e teor de proteína dos grãos (\%).

TABELA 7. Análise de variância (teste F) de produção de grãos $(\mathrm{g})$, peso de 100 grãos (g) e teor de proteína dos grãos (\%).

\begin{tabular}{lcccc}
\hline $\begin{array}{l}\text { Causa de } \\
\text { variação }\end{array}$ & G.L. & $\begin{array}{l}\text { Produção } \\
\text { de grãos }\end{array}$ & $\begin{array}{r}\text { Peso de } \\
100 \text { grãos }\end{array}$ & $\begin{array}{r}\text { Proteína } \\
\text { dos grãos }\end{array}$ \\
\hline Blocos & 1 & 0,82 & $11,33^{* *}$ & 2,77 \\
Tratamentos & 8 & $62,56^{* *}$ & $5,77^{* *}$ & 2,95 \\
Resíduo & 8 & & & \\
\hline
\end{tabular}

Total $\quad 17$

\begin{tabular}{llll}
\hline $\mathrm{CV}(\%)$ & 4,67 & 4,13 & 5,75 \\
\hline
\end{tabular}

* = significativo a $5 \%$

** = significativo a $1 \%$

Os resultados para este parâmetro, mostraram que défice hídrico moderado, ocorrendo individualmente nos estádios de máximo perfilhamento e grão leitoso, não afetou a produção final de grãos; contrariamente, quando o mesmo défice moderado se manifestou no estádio de florescimento, diminuiu significativamente a produção. Com a ocorrência de défice intenso, em cada um dos estádios fenológicos, houve decréscimo significativo na produção de grãos, sendo a maior queda observada no estádio de florescimento. Ciclos repetidos de défices moderados ou intensos, comprometeram o crescimento e desenvolvimento da cultura, diminuindo significativamente a produção final de grãos.

No que se refere ao peso de 100 grãos, a análise de variância expressou diferença significativa, entre tratamentos e blocos, à nível de $1 \%$ de probabilidade, mostrando tendência à diminuição do peso de 100 grãos, do tratamento 1 (irrigado diariamente) ao tratamento 9 (submetido a 3 ciclos de défices hídricos intensos), o qual mostrou o menor resultado. Comparando-se as médias dos vários tratamentos, através do teste Tukey, verifica-se que o maior valor, para o peso de 100 grãos, ficou com o tratamento 1 (irrigado), diferindo estatísticamente apenas em relação aos tratamentos 5 (défice intenso no estádio de máximo perfilhamento), 7 (défice intenso no estádio de grão leitoso) e 9 (défices intensos nos três estádios), sem apresentar significância em relação aos demais tratamentos.

Sobre o teor de proteína dos grãos, a análise de variância (teste $F$ ) não mostrou significância estatística entre os diferentes tratamentos. Contudo, quando da comparação das médias pelo teste Tukey, verificou-se diferença significativa apenas entre os tratamentos 1 (irrigado) e 9 (défices intensos hos três estádios) ficando, respectivamente, com o menor e maior valor para este parâmetro. De qualquer forma, independentemente da análise estatística, houve tendência ao aumento do teor de proteína dos grãos, com a diminuição do potencial de água no solo. 


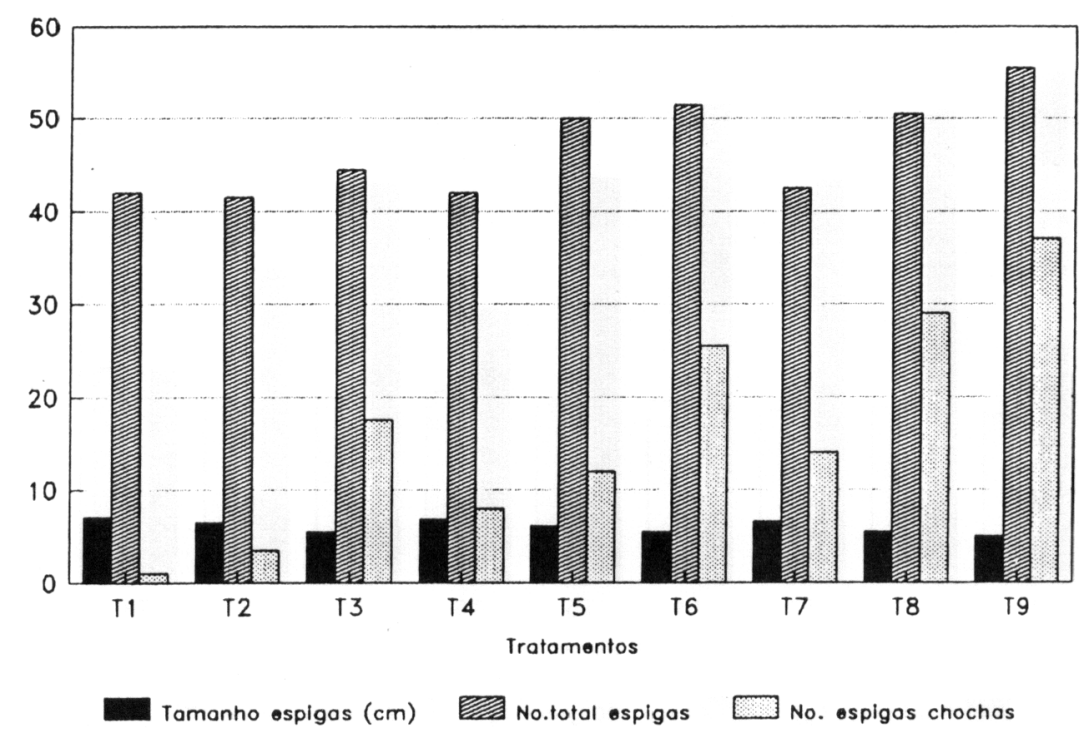

Figura 2. Médias de tamanho médio das espigas $(\mathrm{cm})$, número total e número de espigas chochas por tratamento.

A TABELA 8 e Figura 2 apresentam as médias para o tamanho de espigas, número total e de espigas chochas por tratamento, sendo que a análise de variância pode ser vista na TABELA 9.

TABELA 8. Tamanho médio das espigas (cm), número total e número de espigas chochas por tratamento.

\begin{tabular}{lllr}
\hline Trat. & $\begin{array}{l}\text { Tamanho } \\
\text { de espigas }\end{array}$ & $\begin{array}{l}\mathrm{N}^{0} \text { total } \\
\text { de espigas }\end{array}$ & $\begin{array}{c}\mathrm{N}^{0} \text { espigas } \\
\text { chochas }\end{array}$ \\
\hline 1 & $7,2 \mathrm{~A}(*)$ & $42,0 \mathrm{~A}$ & $1,0 \mathrm{E}$ \\
2 & $6,5 \mathrm{AB}$ & $41,5 \mathrm{~A}$ & $3,5 \mathrm{E}$ \\
3 & $5,6 \mathrm{AB}$ & $44,5 \mathrm{~A}$ & $17,5 \mathrm{C}$ \\
4 & $6,9 \mathrm{~A}$ & $42,0 \mathrm{~A}$ & $8,0 \mathrm{DE}$ \\
5 & $6,2 \mathrm{AB}$ & $50,0 \mathrm{~A}$ & $12,0 \mathrm{CD}$ \\
6 & $5,5 \mathrm{AB}$ & $51,5 \mathrm{~A}$ & $25,5 \mathrm{~B}$ \\
7 & $6,6 \mathrm{AB}$ & $42,5 \mathrm{~A}$ & $14,0 \mathrm{CD}$ \\
8 & $5,6 \mathrm{AB}$ & $50,5 \mathrm{~A}$ & $29,0 \mathrm{~B}$ \\
9 & $5,1 \mathrm{~B}$ & $55,5 \mathrm{~A}$ & $37,0 \mathrm{~A}$
\end{tabular}

(*) As letras representam a comparação, em cada coluna, pelo teste Tukey, sendo que letras iguais, representam médias que não diferem significativamente entre si.

A análise de variância, para o tamanho de espigas, mostrou diferença significativa entre tratamentos, nível de $5 \%$ de probabilidade. No entanto, quando da aplicação do teste Tukey às médias de cada um dos tratamentos, verifícou-se apenas significância dos tratamentos 1 (irrigado) e 4 (défice moderado no estádio de grão leitoso), que tiveram os maiores valores, em relação ao tratamento 9 (sob três ciclos intensos de défices), o qual apresentou o menor resultado, não havendo diferença significativa entre os demais tratamentos.

TABELA 9. Análise de variância (teste F) de tamanho de espigas $(\mathrm{cm})$, número total e número de espigas chochas.

\begin{tabular}{|c|c|c|c|c|}
\hline $\begin{array}{l}\text { Causa de } \\
\text { variação }\end{array}$ & G.L. & $\begin{array}{l}\text { Tamanho } \\
\text { espigas }\end{array}$ & $\begin{array}{l}N^{0} \text { total } N \\
\text { de espigas }\end{array}$ & $\begin{array}{l}N^{\circ} \text { espigas } \\
\text { s chochas }\end{array}$ \\
\hline $\begin{array}{l}\text { Blocos } \\
\text { Tratamentos } \\
\text { Resíduo } \\
\text { Total }\end{array}$ & $\begin{array}{c}1 \\
8 \\
8 \\
17\end{array}$ & $\begin{array}{l}0,23 \\
4,92 *\end{array}$ & $\begin{array}{l}0,08 \\
4,00 *\end{array}$ & $\begin{array}{c}0,88 \\
94,15 * *\end{array}$ \\
\hline CV (\%) & & 7,13 & 3,94 & 10,74 \\
\hline
\end{tabular}

* = significativo a $5 \%$

** $=$ significativo a $1 \%$

Mesmo sem a ocorrência de significância, verificou-se maior sensibilidade à défices hídricos, com relação diminuição do 
tamanho médio das espigas, no estádio de florescimento. Esta tendência pode ser vista nos tratamentos 3 e 6, submetidos a défices moderados e intensos, respectivamente, ambos no estádio de florescimento, os quais apresentaram decréscimo mais acentuado no tamanho médio das espigas, quando comparados aos tratamentos mantidos sob os mesmos défices em outros estádios.

O número total de espigas mostrou significância entre tratamentos (teste $F$ ), à nível de 5\% de probabilidade, embora a comparação das médias, através do teste Tukey, não expressou tal significância. De qualquer maneira, vê-se que os tratamentos 5 (défice intenso no perfilhamento), 6 (défice intenso no florescimento), 8 (défice moderado nos três estádios) e 9 (défice intenso nos três estádios), tiveram um aumento relativo no número total de espigas, quando comparados com os demais tratamentos. Este comportamento, parece estar relacionado ao aumento do número de perfilhos, observado nesses tratamentos, sugerindo ser uma resposta da planta a condições adversas.

No tocante ao número de espigas chochas, a análise de variância evidenciou significância estatística para tratamentos, à nível de $1 \%$ de probabilidade. Assim, quando da comparação das médias de tratamentos, pelo teste Tukey, observamos que o maior número de espigas chochas ocorreu no tratamento 9 (défices intensos nos três estádios), com valores extremamente elevados (37 espigas chochas/tratamento), seguido dos tratamentos 8 (défices moderados nos três estádios) e 6 (défice intenso no florescimento), ficando os resultados mais baixos para os tratamentos 2 (défice moderado no perfilhamento) e 1 (irrigado), o qual apresentou o menor valor (1 espiga chocha/tratamento). Este componente da produção, mostrou-se o mais sensível ao défice hídrico, sendo um dos principais responsáveis pelo decréscimo na produção de grãos, onde o estádio de florescimento caracterizou-se novamente, como - mais susceptível à défice de água.

Vários trabalhos citados na literatura, concordam com os resultados obtidos no presente estudo, afirmando existir aumento do número de espigas chochas, com a diminuição do potencial de água no solo, sobretudo no período compreendido entre a emergência o a antese, sendo um dos principais responsáveis pelo decréscimo da produtividade em plantas de cevada (LAWLOR et al., 1981).

\section{CONCLUSŌES}

1- Os efeitos de défices hídricos, sobre os parâmetros estudados, variaram com a intensidade, duração e estádio fenológico da cultura.

2- Défice hídrico moderado, ocorrendo individualmente nos estádios de máximo perfilhamento e grão leitoso, não afetou a produção de grãos; contrariamente, quando o mesmo défice moderado se manifestou no estádio de florescimento, diminuiu significativamente a produção.

3- A ocorrência de défice hídrico intenso, em cada um dos estádios fenológicos, bem cono ciclos repetidos de défices (moderados ou intensos), levaram à diminuições significativas na produção de grãos.

4- Independentemente da intensidade, o estádio de florescimento se mostrou o mais sensível ao défice hídrico.

5- Houve tendência ao aumento do teor de proteína dos grãos, quando da diminuição do potencial de água no solo, sobretudo no tratamento submetido a três ciclos intensos de défices.

6- O número de espigas chochas, foi o componente de produção mais afetado, pela diminuição do potencial de água no solo.

7- O manejo da irrigação na cultura da cevada, quando se busca a máxima eficiência no uso da água, deve levar em conta os diferentes estádios fenológicos.

\section{AGRADECIMENTOS}

Ao Prof.Dr. Antonio Evaldo Klar, do Departamento de Engenharia Rural, da Faculdade de Ciências Agrónômicas/UNESP, Botucatu, SP, pela colaboração e incentivo, e ao $\mathrm{CNPq}$, pelo apoio financeiro.

\section{REFERENCIAS BIBLIOGRÁFICAS}

ASPINALL, D.; NICHOLLS, P.B.; MAY, L.H. The effects of moisture stress on the growth of barley. Australian Journal of Agricultural Research, Melbourne, v.15, p.729-745, 1964. 
BEGG, J.F.; TURNER, N.C. Crop water deficits. Advances in Agronomy, New York, v.28, p.161-217, 1976.

BRASIL. Portaria $n^{\circ}$ 532, de 20 de julho de 1976. Regras para análise de sementes. Diário Oficial da União, Brasilia, v.114, n.49, p.10356, 5 ago. 1976. Seçåo 1, pt.1.

BRASIL. Portaria $n^{\circ} 389$, de 9 de maio de 1971. Normas de qualidade da cevada industrial. Diário Oficial da União, Brasília, v.107, n.90, p.6712-6714, 14 maio 1979. Seção 1, pt.1.

CARVAlHo, W.A.; ESPINDOLA, C.R.; PACCOLA, A.A. Levantamento de solos da Fazenda Lageado. Botucatu: UNESP, Faculdade de Ciências Agronômicas, 1983. 95p. (Boletim Científico, 1).

DENMEAD, O.T.; SHAW, R.H. The effects of soil moisture stress at different stages of growth on the development and yield of corn. Agronomy Journal, Madison, v.52, n.5, p.272-274, 1960 .

FARIA, M.A. Comportamento de seis genótipos de cevada (Hordeum vulgare L.) sob regime de sequeiro e de irrigação, na região de Botucatu-SP. Botucatu, 1990. 137p. Tese (Doutorado) - Faculdade de Ciências Agronômicas, UNESP.

GARDNER, W.R.; NIEMAN, R.H. Lower' limit of water availability to plants. Science, Washington, v.143, p.1460-1462, 1964.

KLAR, A.E.; CATÂNEO, A.; DENADAI, I.A.M. $e t$ al. Medidas de adaptação de plantas de trigo a déficits hídricos. Cientifica, Jaboticabal, v.13, n.1/2, p.117-127, 1985 .

KLAR, A.E.; DENADAI, I.A.M.; CATÂNEO, A. Resistência à seca de nove cultivares de trigo no estado de São Paulo. In: CONGRESSO NACIONAL DE IRRIGAÇÃO E DRENAGEM, 8, 1988 , Florianópolis. Anais... Florianópolis: ABID, 1988. v.1, p.181-201.

KOSLOWSKI, T.T. Water deficits and plant growth. New York: Academic Press, 1968. 2v.

KRAMER, P.J. Plant and soil water relationships: a modern synthesis. New York: Mc Graw-Hill, 1969. 538p.

LAWLOR, D.W.; DAY, W.; JOHNTON, A.E. Growth of sptring barley under drought: crop development, photosynthesis, dry-matter accumulation and nutrient content. Journal of Agricultural Science, Cambridge, v.96, p.167-186, 1981.
MILLAR, A.A. Manejo racional da irrigação: uso de informaçöes básicas sobre diferentes culturas. Brasilia: IICA, 1984. 56p.

MINELLA, E.; WENDT, W.; DA LUZ, W.C. et al. Recomendaçóes técnicas para o cultivo da cevada cervejeira. Circular Técnica do Centro Nacional de Pesquisa do Trigo, Passo Fundo, n.1, p.1-23, 1981.

ROBINS, J.S.; DOMINGO, C.E. Some effects of severe soil moisture deficits at specific growth stages in corn. Agronomy Journal, Madison, v.45, p.618-621, 1953.

RODRIGUES, J.D. A influência de diferentes regiōes de umidade do solo em gladíolos. Botucatu, 1973. 92p. Tese (Doutorado) - Faculdade de Ciências Médicas e Biológicas, UNESP.

SALTER, P.J.; GOODE, J.E. Crop responses to water at different stages of growth. England: Commonwealth Agricultural Bureaux, 1967. 246p.

SCALOPPI, E.J. Efeito de défices hídricos em diferentes estágios fenológicos da batata. Botucatu, 1973. 103p. Tese (Doutorado) - Faculdade de Ciências Médicas e Biológicas, UNESP.

SHARMA, R.A.; GUPTA, R.K.; SHARMA, R. Influence of soil water potential on the growth of barley. Indian Society of Soil Science Journal, New Delhi, v.34, p.707-712, 1986.

SLATYER, R.O. Plant-water relationships. London: Academic Press, 1967. 366 p.

URCHEI, M.A. Efeitos de défices hídricos, em três estádios fenológicos, da cultura da cevada (Hordeum vulgare L.). Botucatu, 1992. 164p. Dissertaçāo (Mestrado) - Faculdade de Ciências Agronômicas, UNESP.

WAUGH, D.L.; FITTS, J.W. Estudos para interpretação de ań́lises de solo: de laboratório e em vasos. Boletim Técnico, n.3, p.1-33, 1966.

WELLS, S.A.; DUBETZ, S. Reaction of two barley cultivars to a period of soil water stress during heading. Canadian Journal of Plant Science, Ottawa, v.30, p.701-704, 1970.

Recebido para publicação em 20.01.94

Aceito para publicação em 17.03.94 